RESEARCH PAPER

\title{
Hand rolling cigarette papers as the reference point for regulating cigarette fire safety
}

\author{
M Laugesen, M Duncanson, T Fraser, V McClellan, B Linehan, R Shirley
}

Tobacco Control 2003;12:406-410

\begin{abstract}
Aim: To compare the burning characteristics of the tobacco and paper of manufactured and hand rolled cigarettes, and set a fire safety standard of manufacture to largely reduce the fire risk from discarded cigarettes.

Methods: (1) Cigarette extinction test of ignition strength: 40 cigarettes per brand, lit and placed on 15 layers of filter paper, in accordance with ASTM test standard E2187-02. (2) Citrate extracted by $0.1 \mathrm{~N}$ hydrochloric acid from cigarette papers and from tobacco in manufactured cigarettes, the supernatant analysed by high performance liquid chromatography using ultraviolet visual light spectrophotometer. (3) Survey of 750 nationally representative adults age 18 years and over, by telephone, including 184 smokers.

Materials: (a) New Zealand made Holiday, and Horizon, and US made Marlboro manufactured cigarettes; (b) US manufactured Merit with banded paper; (c) Holiday, Horizon and Marlboro hand rolling tobaccos, hand rolled in Rizla cigarette papers; (d) manufactured cigarettes as in (a), reconstructed using Rizla hand rolling cigarette papers.

Results: 1. (a) For each brand of manufactured cigarettes, $40 / 40$ burnt full length; (b) for Merit banded paper cigarettes 29/40 (73\%) burnt full length; (c) for each brand of hand rolled cigarettes $0 / 40$ burnt full length; (d) 0/40 manufactured cigarettes reconstructed with Rizla hand rolling paper burnt full length. 2. Citrate content: (a) In manufactured cigarette papers: $0.3-0.8 \mathrm{mg}$; in tobacco of manufactured cigarettes: Holiday 0, Horizon 0, Marlboro 8.8 mg; (b) Merit: in banded paper $0.418 \mathrm{mg}$; in tobacco $10.23 \mathrm{mg}$; (c) In hand rolled cigarettes: in the papers $<0.08 \mathrm{mg}$; in hand rolled tobacco 13.3-15.0 mg; (d) In hand rolling papers of reconstructed cigarettes: $<0.018 \mathrm{mg}$. 3. Requiring manufactured cigarettes to compulsorily self-extinguish when left unattended was supported by $67 \%$ of smokers, $61 \%$ of manufactured cigarette smokers, $82 \%$ of hand rolled smokers, and by $68 \%$ of non-smokers.

Conclusion: The wrapping paper is a key determinant of whether or not unpuffed cigarettes burn their full length. Using international test methods, popular brands of manufactured cigarettes all burnt full length, but none did so when re-wrapped in hand rolling cigarette paper. This provides a ready-to-hand smoker acceptable standard for reducing ignition potential from manufactured cigarettes, as a basis for regulation or litigation.
\end{abstract}

See end of article for authors' affiliations

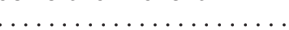

Correspondence to: Murray Laugesen, PO Box 32099, Devonport, North Shore, Auckland 1330 New Zealand; laugesen@ healthnz.co.nz

Received 19 May 2003 Accepted

9 September 2003 ty this paper we compare the burning properties of different types of cigarette, with a view to writing a feasible fire safety standard for cigarette manufacture, one that is acceptable to most smokers.

Smokers accept that a manufactured cigarette, alone of all tobacco products, burns its full length if left unattended. In contrast, hand rolled cigarettes, bidis, cigars, and pipes, if not frequently puffed, require relighting. It follows that manufactured cigarettes burn their full length because they are manufactured to do so, and that the method of their manufacture could probably be changed to ensure this did not happen, and that cigarette manufacturers must know how this can be done.

\section{Problem statement}

The dangers of fire associated with tobacco smoking have been recognised for over 100 years. ${ }^{1}$ Ignition of furnishings by smoking materials in houses is by far the most common cause of death by fire. ${ }^{2}$

Smoking materials, including discarded cigarettes, are the known heat source for an important proportion of fatal fires in many countries. ${ }^{3-8}$ From 1991 to 1997 cigarettes were a probable heat source of $20 \%$ of 184 unintentional domestic fire related deaths in New Zealand. ${ }^{9}$ Fires originating from cigarettes are significantly more likely to be fatal than fires due to other heat sources. ${ }^{10} 11$
Laboratory testing showed variation in ignition strength between brands of manufactured cigarettes sold in the USA, although the top selling brands were all strong igniters, ${ }^{12}{ }^{13}$ indicating that manufacturers could influence the ignition strength. Hand rolled cigarettes were not considered in either of these two studies.

For the last 25 years at least, manufacturers have resisted introducing fire retardant (reduced ignition potential or RIP) cigarettes. The tobacco industry made payments to scores of fire organisations in the 1990s to dampen calls for a fire safe product.

The industry argued that RIP cigarettes ${ }^{14}$ :

(1) Were unacceptable to consumers. Despite their tendency to self extinguish, hand rolled cigarettes are popular in many countries. In 2000, "other manufactured tobacco", mainly used for hand rolling, comprised over $40 \%$ of total tobacco products consumption in Norway, and the Netherlands; over $20 \%$ in Denmark, Belgium, and New Zealand; and over $10 \%$ in Finland, Iceland, and Sweden. ${ }^{15}$

(2) Increased toxicity. Manufacturers' documents show they know how to make RIP cigarettes without increasing tar

Abbreviations: ASTM, American Standard Test Method; NIST, National Institute of Standards and Technology; RIP, reduced ignition potential 
yields in the smoke. ${ }^{14}{ }^{16}$ Disease risks to smokers from occasionally re-lit cigarettes, whether hand rolled or RIP, would be similar, and the fire risk to others living in the same building would be reduced. In any case, governments can separately regulate to enforce upper limits to cigarette smoke toxicity across all brands.

(3) Could not be tested accurately to predict fire safety. Until recently, the National Institute of Standards and Technology (NIST) in the USA used two methods for testing ignition strength of cigarettes. In the mock-up ignition method a lit cigarette was placed on a sheet of fabric over a block of flexible polyurethane foam, to see whether or not the foamfabric substrate ignited. Due to difficulties in obtaining and standardising the fabrics, NIST in 2002 abandoned this mock ignition method. Only one standard is needed for regulation, and US NIST now uses the cigarette extinction test, using filter papers available internationally. ${ }^{17}$ NIST has rated the cigarette extinction test "a strong indicator as to whether a reduction in cigarette-initiated fires might be expected". ${ }^{13}$

(4) Were not the primary problem in cigarette caused fires. While the behaviour of smokers is a factor in cigarette initiated fires, almost all cigarettes lit are extinguished safely, and so further education of smokers is unlikely to reduce cigarette fire injury rates significantly. ${ }^{18}$ Although domestic fire alarms are associated with a lower risk of residential fire fatalities, ${ }^{5} 19$ such alarms are less effective in cigarette fires, where the victim is often too close to the fire to be able to escape, especially if impaired by drugs or alcohol. ${ }^{19-21}$

\section{MATERIALS AND METHOD Materials}

All materials were purchased just before testing. Cigarette papers were purchased in packets of 100. Brands for citrate estimations were Zig Zag (made in France), and Rizla (Imperial Tobacco Company, European Union). Only Rizla paper was used for the cigarette extinction tests-medium weight Rizla was used for hand rolling. For the reconstructed cigarettes half were rolled in medium weight Rizla and half in light weight Rizla.

Manufactured cigarettes tested were king size filter: (a) Holiday regular strength (British American Tobacco, manufactured in New Zealand) which comprised $20 \%$ of manufactured cigarette volume sales in $2001^{22}$; (b) Horizon regular strength (Imperial, manufactured in New Zealand), 6\% of sales $^{22}$; (c) Marlboro regular strength (Philip Morris, manufactured in the USA), $2 \%$ of sales ${ }^{22}$; (d) Merit Lights with banded (PaperSelect) paper, manufactured in the USA, sales not reported, ${ }^{22}$ and described on the packet attachment as "a cigarette that may put itself out when resting in an ashtray. It may be less likely to ignite certain fabrics". Hand rolled cigarette tobaccos of the same brands were tested, except Merit which is not sold in that form.

Reconstructed cigarettes were made by slitting the paper wrapping the tobacco rod of the manufactured cigarette, removing all tobacco, and re-wrapping that tobacco in hand rolling paper $(70 \mathrm{~mm}$ in length, using the filter from the manufactured cigarette, trimmed to give a tobacco rod of 58$60 \mathrm{~mm})$.

Hand rolling tobacco cigarettes were wrapped around separately sold filters and trimmed to a tobacco rod length $(55 \mathrm{~mm})$ close to that of manufactured cigarettes, (58$60 \mathrm{~mm}$ ) and to a diameter of $7 \mathrm{~mm}$ approximately, employing an experienced operator and a Rizla hand roller. The diameter of the manufactured and reconstructed cigarettes was $7-8 \mathrm{~mm}$. To make cigarettes from hand rolled tobacco, the tobacco was weighed out to match tobacco weights in the manufactured cigarettes of the same brand. Density of the tobacco in the rod was thus similar for manufactured, reconstructed, or hand rolling tobacco cigarettes of the same brand, but varied a little between brands.

\section{Method}

\section{Ignition strength test}

BRANZ Ltd (formerly the Building Research Association of NZ) performed this test at its Judgeford, Wellington laboratory under the supervision of a senior fire engineer using equipment and method specified in ASTM (American Standard Test Method) E2187-02. ${ }^{17}$ In October 2002, using the cigarette extinction method, 40 cigarettes of each brand were serially lit and picked up in a holder and, once $15 \mathrm{~mm}$ of the cigarette was burnt, placed on filter paper, and timed and measured from that point until self extinction or until the whole tobacco rod $(55-60 \mathrm{~mm})$ was burnt. Thus cigarettes which burnt full length burnt a further $40-45 \mathrm{~mm}$ along the rod. ${ }^{23}$ The test permits a choice of either 3,10 , or 15 layers of filter paper. We used 15 layers which should absorb more heat than 10 layers, cooling the lit end more rapidly and leading to earlier self extinguishment. Fifteen layers have given a lower percentage of full length burns than 10 layers on testing the same cigarettes. ${ }^{13}{ }^{16}$ Merit cigarettes were retested on 10 layers of filter paper in August 2003.

\section{Citrate}

Out of three packets each of Zig-Zag and Rizla cigarette papers purchased in Auckland in 2002, e-lab staff at Ruakura, Hamilton extracted 20 papers per brand with $50 \mathrm{ml}$ of $0.1 \mathrm{~N}$ hydrochloric acid, soaking the papers overnight, then shaking at 120 strokes per minute for 30 minutes, and centrifuging the extract for 20 minutes at $2000 \mathrm{rpm}$. Clear supernatant was submitted to Hort Research, Ruakura for citrate determination by high performance liquid chromatography using an ultraviolet/visual light spectrophotometer. Tobacco $(1.000 \mathrm{~g})$ was also extracted in $50 \mathrm{ml} 0.1 \mathrm{~N} \mathrm{HCl}$, as above, then filtered through glass fibre paper (Toya brand); an acid blank was also filtered.

\section{Opinion survey}

A nationally representative telephone sample of 750 adults aged 18 years and over were interviewed by UMR Research Ltd Wellington in April 2003, as part of an omnibus survey. The survey used computer assisted telephone interviewing of private households, stratified by 23 telephone directory regions, using randomised dialling to include unlisted numbers, to ask "Research has shown that cigarettes that go out more quickly if you don't puff on them are less likely to cause house fires than other cigarettes. Would you support or oppose making it compulsory for all ready-made, tailormade cigarettes sold in New Zealand to go out quickly when they are not being puffed?'”24

\section{RESULTS \\ Physical characteristics}

Cigarette papers for hand rolling measured $70 \times 38 \mathrm{~mm}$. Light thickness Rizla papers weighed 41-42 mg, and medium thickness weighed $47-48 \mathrm{mg}$ each (range of brand averages). In manufactured cigarettes (total length $82-84 \mathrm{~mm}$, tobacco rod $58-60 \mathrm{~mm}$, filter $23-27 \mathrm{~mm}$ ) the paper wrapping the tobacco column as far as the tipping paper round the filter weighed 4l-42 mg.

\section{The ignition strength test}

All manufactured cigarettes tested (three brands, 40 cigarettes per brand) burnt their full length, significantly more than the $73 \%(29 / 40)$ of Merit banded paper cigarettes which burnt full length $(\mathrm{p}<0.001)$ (table 1$)$, and more than the $75 \%$ (30/40) Merit banded paper cigarettes burning full length when tested on 10 layers of filter paper. In contrast, 
Table 1 Ignition strength test ${ }^{17}$ of manufactured, reconstructed, and hand rolled cigarettes

\begin{tabular}{|c|c|c|c|c|}
\hline $\begin{array}{l}\text { Product, and length of the tobacco rod } \\
\text { (mm) up to tipping paper }\end{array}$ & $\begin{array}{l}\text { Self extinguished in } \\
\text { holder number }(\%)\end{array}$ & $\begin{array}{l}\text { Self extinguished on filter paper } \\
\text { number (average burn length } \\
\text { along rod beyond the } 15 \mathrm{~mm} \\
\text { mark, in } \mathrm{mm} \text { ) }\end{array}$ & $\begin{array}{l}\text { Cigarettes burnt full } \\
\text { length number }(\%)\end{array}$ & $\begin{array}{l}\text { Average (SD) burn time } \\
\text { (minutes: seconds) }\end{array}$ \\
\hline \multicolumn{4}{|c|}{ Manufactured cigarette by brand ( $n=40$ for each brand) } & 3 brands: $12: 18(0: 59)$ \\
\hline Marlboro 58 & $0(0)$ & $0(43)$ & $40(100)$ & $11: 52(1: 48)$ \\
\hline Holiday 58 & $0(0)$ & $0(43)$ & $40(100)$ & $12.10(0: 47)$ \\
\hline Horizon 60 & $0(0)$ & $0(45)$ & $40(100)$ & $12.54(0: 57)$ \\
\hline \multicolumn{5}{|c|}{ Manufactured cigarette with banded paper $(n=40)$} \\
\hline Merit 51 & $0(0)$ & $10(32)$ & $29(73)$ & $9.57(1: 52)$ \\
\hline \multicolumn{4}{|c|}{ Hand rolling tobaccos rolled in medium weight Rizla cigarette paper ( $n=40$ for each brand) } & 3 brands: $0: 31$ (1:25) \\
\hline Marlboro 55 & $38(95)$ & $2(1)$ & $0(0)$ & $0: 11(0: 47)$ \\
\hline Holiday 55 & $40(100)$ & $0(0)$ & $0(0)$ & $0: 00(0: 00)$ \\
\hline Horizon 55 & $26(65)$ & $14(2)$ & $0(0)$ & $1: 21(2: 06)$ \\
\hline \multicolumn{4}{|c|}{ Manufactured cigarettes reconstructed with light weight Rizla cigarette paper ( $n=20$ for each brand) } & 3 brands: $0: 00$ \\
\hline Marlboro 58 & $20(100)$ & $0(0)$ & $0(0)$ & $0: 00$ \\
\hline Holiday 58 & $20(100)$ & $0(0)$ & $0(0)$ & $0: 00$ \\
\hline Horizon 60 & $20(100)$ & $0(0)$ & $0(0)$ & $0: 00$ \\
\hline \multicolumn{4}{|c|}{ Manufactured cigarettes reconstructed with medium weight Rizla cigarette paper ( $n=20$ for each brand) } & 3 brands: $1: 16(1: 57)$ \\
\hline Marlboro 58 & $14(70)$ & $6(0)$ & $0(0)$ & $0: 57(1: 31)$ \\
\hline Holiday 58 & $10(50)$ & $10(2)$ & $0(0)$ & $2: 10(2: 29)$ \\
\hline Horizon 60 & $16(80)$ & $4(1)$ & $0(0)$ & $0: 42(1: 28)$ \\
\hline
\end{tabular}

none of the 240 cigarettes wrapped in hand rolling paper burnt its full length, whether part of a reconstructed cigarette or part of a hand rolling tobacco cigarette (table 1), significantly less full length burns than with banded paper $(\mathrm{p}<0.0001)$.

\section{Burn time to self extinguishment}

After the burn reached $15 \mathrm{~mm}$ along the tobacco rod, and the cigarette was placed on the filter paper, times to self extinguishment or completion of a full length burn (table 1) were:

(a) Manufactured cigarettes (mean 12 mins 18 s, range 1015 mins).

(b) Banded paper Merit cigarettes (mean 9 mins 57 s, range 5-14 mins). The difference in means between (a) and (b) was significant $(\mathrm{p}<0.001)$ (table 1$)$. Counting only full length burns, Merit cigarettes burnt an average 9 mins $55 \mathrm{~s}$ (SD 1 min $9 \mathrm{~s}$ ), more rapidly than other manufactured cigarettes $(\mathrm{p}<0.0001)$; banded paper did not slow the rate of burn along the tobacco rod. (c) Hand rolled cigarettes, in contrast, self extinguished after an average $31 \mathrm{~s}$.

(d) Reconstructed cigarettes (half tested with light and half tested with medium Rizla paper) burned an average $38 \mathrm{~s}$ (SD 1 min $31 \mathrm{~s}$ ), not significantly different from the $31 \mathrm{~s}$ result, but together or separately significantly shorter than for banded paper Merit cigarettes $(\mathrm{p}<0.001)$ (table 1$)$. The burn time average for hand rolled cigarettes rolled in medium weight paper was $44 \mathrm{~s}$ shorter than for reconstructed cigarettes rolled in the same paper $(p<0.01)$ (table 1).

Once the burn reached $15 \mathrm{~mm}$ along the tobacco rod, cigarettes wrapped in hand rolled paper, whether hand rolling tobacco cigarettes or reconstructed, stayed alight for no more than $5 \%$ as long as unaltered manufactured cigarettes, and no more than $6 \%$ of the average burn time of banded paper cigarettes.

\section{Citrate in papers and tobacco}

Significant levels of citrate were found in the paper wrapping the tobacco rod of all manufactured cigarettes tested, which

\begin{tabular}{|c|c|c|c|}
\hline Product & $\begin{array}{l}\text { Country of } \\
\text { manufacture }\end{array}$ & $\begin{array}{l}\text { Citrate } \mathrm{mg} \text { per paper } \\
\text { (\% by weight) }\end{array}$ & $\begin{array}{l}\text { Citrate } \mathrm{mg} \text { per } \\
\text { tobacco column }\end{array}$ \\
\hline \multicolumn{4}{|c|}{$\begin{array}{l}\text { In hand rolled cigarette tobacco } \\
\text { and papers }\end{array}$} \\
\hline Holiday & New Zealand & Not applicable & $14.94^{*}$ \\
\hline Horizon & New Zealand & Not applicable & $13.32^{*}$ \\
\hline Marlboro & Belgium & Not applicable & $14.96^{*}$ \\
\hline Zig Zag: & France & & Not applicable \\
\hline Rice & & $<0.0015(<0.003)$ & \\
\hline Blue & & $<0.0015(<0.004)$ & \\
\hline Grey & & $<0.0015(<0.003)$ & \\
\hline Rizla: & European Union & & Not applicable \\
\hline Red & & $0.0017(0.004)$ & \\
\hline Green & & $0.037(0.077)$ & \\
\hline Blue & & $0.033(0.079)$ & \\
\hline \multicolumn{4}{|c|}{ In manufactured cigarettes } \\
\hline Holiday & New Zealand & $0.405(1.001)$ & $<0.018$ \\
\hline Horizon & New Zealand & $0.302(0.743)$ & $<0.018$ \\
\hline Marlboro & USA & $0.755(1.798)$ & 8.76 \\
\hline Merit & USA & $0.418(0.853)$ & 10.23 \\
\hline
\end{tabular}


all burnt full length (table 2). Banded paper Merit cigarettes also contained citrate, and most burnt full length.

In contrast, hand rolling papers of the Zig Zag brand contained no detectable citrate, Rizla brand papers contained barely detectable levels (table 2), and no cigarette wrapped in these hand rolled papers burnt full length. The burning characteristics of manufactured cigarettes were thus closely associated with the citrate levels in the paper rather than in the tobacco.

Tobacco in the two New Zealand brands of manufactured cigarettes did not contain detectable citrate, whereas tobacco from Marlboro and Merit cigarettes contained approximately $8.8-10.2 \mathrm{mg}$ per cigarette. Hand rolled cigarette tobacco contained more citrate: $13.4-15.0 \mathrm{mg}$ per cigarette assuming the same weight of tobacco as the manufactured cigarette of the same brand. Citrate level of the tobacco itself was not related to ignition propensity. All Holiday and Horizon manufactured cigarettes burnt full length despite containing no citrate in their tobacco, whereas the tobacco of Marlboro cigarettes which also burnt full length, contained appreciable citrate.

\section{Opinion survey}

Of the nationally representative sample of 750 adults aged 18 and over, $184(25 \%)$ were smokers of whom $47 \%$ smoked manufactured cigarettes, $40 \%$ hand rolled, 12\% both. Support for making all cigarettes self extinguish (with the percentages opposing in brackets, and the undecided percentage omitted) was: all smokers $67 \%(27 \%)$, manufactured cigarette smokers $61 \%(33 \%)$, hand rolled smokers $82 \%(10 \%)$, non-smokers $68 \%(15 \%)$, smokers of both $47 \%$ (53\%). Among the total sample, over half of each subcategory by region, age, sex, ethnicity, occupation, and personal income supported the change, and overall $68 \%$ were in support $(95 \%$ confidence interval (CI) $65 \%$ to $71 \%$ ). ${ }^{24}$

\section{DISCUSSION \\ Principal findings}

All cigarettes wrapped in hand rolling paper self extinguished, whether the tobacco was hand rolling tobacco or taken from manufactured cigarettes. None burnt its full length on the cigarette extinction test.

In contrast, all manufactured cigarettes burnt their full length, except for banded paper Merits of which 73\% burnt full length. The papers that wrapped the tobacco rod of these cigarettes contained appreciable quantities of citrate. Hand rolled cigarettes, characterised by a lack of citrate in the wrapping paper, all self extinguished.

Differences in non-paper factors, such as tobacco density or the way the cigarettes were rolled, could account for the $44 \mathrm{~s}$ difference in burn times between the hand rolled tobacco and the reconstructed cigarettes, when both were wrapped in medium weight paper. In contrast, the difference between manufactured and hand rolled cigarette burn times was nearly 12 mins, and between banded paper and hand rolled, over 9 mins.

Despite the apparent inconvenience, two thirds of smokers and non-smokers sampled were supportive of making cigarettes to self extinguish.

\section{Strengths and weaknesses of the study}

This is the first study to our knowledge testing RIP of hand rolling tobacco or manufactured cigarettes wrapped in hand rolling paper, or of the citrate content of hand rolling paper. The testing of ignition potential in hand rolled cigarettes is subject to some variation in the test sample preparation. Nevertheless all hand rolled cigarettes gave uniform results.
The cigarette brands tested accounted for $28 \%$ of the New Zealand manufactured cigarette market. The cigarette paper brands tested were the two most popular.

This study confirms a US study ${ }^{12}$ showing that popular manufactured cigarette brands tested all burnt full length. We have not measured for paper porosity, tobacco density or rod circumference with respect to the RIP qualities of hand rolled cigarettes. Our results apply only to the brands as purchased and tested. Other batches or brands may behave differently. Where our tests produce results different from those of cigarette manufacturers, further testing by an independent laboratory should resolve the matter.

\section{Strengths and weaknesses of this study in relation to other studies}

A case-control study (cases 564, controls 1611) conducted in eight USA cities in 1992 found that the citrate level in the paper of manufactured cigarettes, analysed as a continuous variable, was not a significant factor in cigarette fires. It compared smokers surviving unintentional cigarette fires, with smokers not involved in such fires. Besides smokers' characteristics, absence of filter, short filter, or porous cigarette paper-factors which increased the air supply to the burning coal of the cigarette-were associated with increased risk of fire. ${ }^{25}$ However, if a certain threshold of citrate is needed to ensure the cigarette keeps burning long enough to cause a fire, then above that threshold higher citrate concentrations might have no extra effect. Reanalysing the data with citrate as a categorical variable, smokers of cigarettes with a paper citrate content of $0.6 \%$ or more were $39 \%$ more likely to be involved in a fire than those smoking cigarettes of citrate $<0.6 \%$ of paper weight (odds ratio $1.39,95 \%$ CI 1.10 to $1.77, \mathrm{p}<0.005)$. Other factors, however, may have confounded this univariate result. In comparison, the papers of the manufactured cigarettes shown in table 2 contained $0.7-1.8 \%$ by weight of citrate.

In the absence of reference test cigarettes, test results on the USA manufactured Marlboro cigarette permit international comparisons, as BRANZ Ltd built the apparatus to, and conducted the test to ASTM specifications. ${ }^{17}$

\section{What this study means}

The cigarette extinction test on 15 layers of filter paper provides a basis for regulating to reduce the ignition strength of manufactured cigarettes. The proposed standard is that no cigarette sold should, if unpuffed, burn its full length (that is, to the filter end of the tobacco rod) on this test.

Any fire safety standard and regulation should cover all cigarettes and require close to $100 \%$ self extinguishment as demonstrated on the cigarette extinction test by cigarettes wrapped in hand rolled paper. The proposed standard is feasible for manufacturers, and would set a higher standard for fire safety than the New York State law (see below).

Our results suggest the proposed fire standard would prevent most cigarette initiated fires-as opposed to fires started with smoking accessories (matches or lighters)-but would not prevent fires occurring while smoking near inflammable gases, or while holding the lit end near, or dropping it on, inflammable materials.

Re-wrapping manufactured cigarettes in hand rolling paper (table 1) reduced the length of the tobacco rod burnt from $58 \mathrm{~mm}$ to $15 \mathrm{~mm}$, and reduced the burn time by $95 \%$. The amount of tobacco burnt reduces proportionate to the length, it is alight for much less time, and the cigarette is a much weaker heat source for causing fire. Simply using hand rolling type paper in manufactured cigarettes should, as for reconstructed cigarettes, greatly reduce ignition propensity. Manufacturers, however, can alter various design parameters to achieve self extinguishment. 


\section{What this paper adds}

Smokers and smoking firefighters have known for many years that whereas manufactured cigarettes burn full length, hand rolled cigarettes self extinguish.

Using a standardised cigarette extinction test we found that manufactured cigarettes, if re-wrapped in hand rolling paper, all self extinguished, just as if they were hand rolled cigarettes, without burning full length. The paper is a key determinant of whether an unpuffed cigarette burns full length. A stringent fire safety standard based on this principle is acceptable to smokers.

In practice, any regulatory standard with penalties attached should permit perhaps one in 100 cigarettes to burn full length on 15 layers of filter paper. Because the reported inter-laboratory reproducibility of the cigarette extinction test is not high (differences of up to 0.4 for 16 replications) ${ }^{26}$ tests for regulatory purposes may be best done in a single independent accredited national laboratory.

New York State's fire standard, ${ }^{26}$ due to take effect in 2003, requires that no more than $25 \%$ of cigarettes burn full length when placed on 10 layers of filter paper in the cigarette extinction test. Repeatability has to be tested once in every 10 test trials (40 tests per cigarette is a complete test trial), with an error of up to 0.19 permitted. ${ }^{26}$ Repeatability and interlaboratory error tolerances have not been determined for the hand rolling paper standard we propose.

Philip Morris reported to the New Zealand's Parliamentary Health Select Committee in 2001 that (only) $8 \%$ of banded paper Merit Lights cigarettes burnt full length on 15 layers of filter paper, and on 10 layers $15 \%$ burnt full length, ${ }^{16}$ thus passing the New York standard. However, in 2003, BRANZ Ltd found that $73 \%$ of banded Merit Lights (29/40) burnt full length on 15 layers of filter paper ${ }^{23}$ (table 1), and 75\% burnt full length on 10 layers, clearly failing the New York standard. The difference $(73-8=65 \%)$ between these two results was not explained by permissible inter-laboratory or repeatability variation; and appear to reflect differences in Merit Lights banded paper cigarettes between 2001 and 2003. It points to the need for each country to have all brands regularly tested at the same independent laboratory.

As cigarettes vary in composition and design, regulation should focus on the RIP standard, rather than on how manufacturers attain that standard. A standard so clear- cut and simply attainable makes regulation to the proposed standard feasible and reasonable to enforce.

\section{Future research and the way forward}

Fire statistics reports which distinguish between fires started by manufactured versus hand rolled cigarettes would greatly help assess the effect of regulation. Governments may wish to estimate what fraction of cigarette fires can be prevented if a standard is adopted. A case-control study ${ }^{25}$ could compare the fire risk of smoking manufactured versus hand rolled cigarettes.

Compliance with any regulated RIP standard would depend on clarity, active enforcement, and adequate penalties. Once smokers become accustomed to self extinguishing cigarettes, they would notice brands which still tended to burn full length.

We envisage the RIP standard eventually forming part of general regulations controlling the toxicity of cigarettes and their smoke, but see no need to delay adoption of an RIP standard for this reason.

Food regulations control food product safety, and regulation of the ignition strength of manufactured cigarettes is overdue. Reducing ignition strength of manufactured cigarettes is an extremely cost effective injury prevention strategy, with an estimated benefit to cost ratio of 500:1, ${ }^{27}$ and is the best use of limited resources even if the numbers involved are small. ${ }^{28}$ Regulation to reduce fire risk is fully justified, to protect those who buy cigarettes and others living in the same building.

\section{ACKNOWLEDGEMENTS}

ASH NZ supported this research with assistance from the Millenium Sports Foundation, Hastings, and KD Kirkby Trust, Tauranga, New Zealand.

\section{Authors' affiliations}

M Laugesen, Health New Zealand, Auckland, New Zealand

M Duncanson, Wellington School of Medicine and Health Sciences, University of Otago, Wellington, New Zealand

T Fraser, ASH NZ (Action on Smoking and Health), Auckland, New Zealand

V McClellan, Research and Evaluation Services, New Plymouth, New

Zealand

B Linehan, Medlab, Hamilton, New Zealand

R Shirley, E-Lab, Hamilton, New Zealand

\section{REFERENCES}

1 Lander M. The tobacco problem, 6th ed. Boston: Lee and Shepherd, 1885.

2 Clarke III FB, Ottoson J. Fire death scenarios and fire safety planning. In: Rapkin C, ed. The social and economic consequences of residential fires. Boston: DC Heath \& Company, 1983:91-99.

3 Baker SP, O'Neill B, Ginsburg MJ, et al. The injury fact book, 2nd ed. New York: Oxford University Press, 1992.

4 Markey E. Slow burn: Fire-safe cigarettes. NFPA Journal 2002;96(6):42-45.

5 Watson L, Gamble J, Schofield R. Fire statistics. United Kingdom 1999. London: Home Office, 2000:89.

6 Brennan P. Victims and survivors in fatal residential building fires. In: Shields J, ed. Victims and survivors in fatal residential building fires. First international symposium on human behaviour in fire. Ireland: Belfast, 1998:157-66.

7 Leistikow BN, Martin DC, Milano CE. Fire injuries, disasters, and costs from cigarettes and cigarette lights: a global overview. Prev Med 2000;31:91-9.

8 Elder AT, Squires T, Busuttil A. Fire fatalities in elderly people. Age \& Ageing 1996;25:214-6.

9 Duncanson M. Unintentional domestic fire injury from fire and flame in Aotearoa New Zealand. Research Report. Wellington: New Zealand Fire Service Commission, 2003.

10 Runyan CW, Bangdiwala SI, Linzer MA, et al. Risk factors for fatal residential fires. N Engl J Med 1992;327:859-63.

11 Istre GR, McCoy MA, Osborn L, et al. Deaths and injuries from house fires. N Engl J Med 2001;344:1911-16.

12 Ohlemiller TJ, Villa KM, Braun E, et al. Quantifying the ignition propensity of cigarettes. Fire and Materials 1995;19:155-69.

13 Gann R, Steckler KD, Ruitberg S, et al. Relative ignition propensity of test market cigarettes (Technical Note 1436). Gaithersburg, Maryland: National Institute of Standards and Technology, 2001.

14 Gunja M, Wayne GF, Landman A, et al. The case for fire safe cigarettes made through industry documents. Tobacci Control 2002;11:346-53.

15 Laugesen M. International tobacco control database, 1960-2000. Health New Zealand Ltd. Accessed May 2003. www.healthnz.co.nz.

16 Scott J. Senior Vice President Philip Morris Asia. Submission to the Government Administration Select Committee. Cigarette (Fire Safety) Bill. Philip Morris (New Zealand) Ltd. (Philip Morris). 2001, including test results dated 20 December 2000

17 ASTM Committee on Fire Standards. Standard test method for measuring the ignition strength of cigarettes. Designation E2187-02. West Conshohocken USA: ASTM International, April 2002.

18 Halbert TA. The fire-safe cigarette: The other tobacco war. Business and Society Review 1999;102:25-36.

19 Marshall SW, Runyan CW, Bangdiwala SI, et al. Fatal residential fires: Who dies and who survives? JAMA 1998;279:1633-7.

20 Hall JR. The other way cigarettes kill. NFPA Journal 1998 (January/ February):58-62.

21 Barillo DJ, Brigham PA, Kayden DA, et al. The fire-safe cigarette: A burn prevention tool. Journal of Burn care and Rehabilitation 2000;21:164-70.

22 Laugesen M. Tobacco manufacturers' returns for calendar year 2001. Report to the Ministry of Health. Wellington: Ministry of Health, 2002.

23 BRANZ Ltd. www.branz.co.nz Reports. FM 3165, and FM 3244. Tests to ASTM E 2187-02b. Porirua: BRANZ Ltd, February and September 2003.

24 UMR Research. Tailor-made cigarettes compulsory to go out quickly (client ASH NZ). Wellington: UMR Research, April 2003; www.umr.co.nz.

25 Karter MJ, Kissinger TL, Miller AL, et al. Cigarette characteristics, smoker characteristics, and the relationship to cigarette fires. Fire Technology 1994;30:400-31

26 New York State Fire Department. Fire safety standards for cigarettes. New York: New York State Fire Department, 2002.

27 Miller T, Levy D. Cost-outcome analysis in injury prevention and control: eightyfour recent estimates for the United States. Medical Care 2000;38:562-82.

28 Roberts I. Research priorities for injury prevention. Injury Prevention 2001;7:2-3. 